\title{
Feasibility of training community health workers to conduct periodontal examinations: a validation study in rural Nepal
}

Daniel J. Erchick ${ }^{1 *}$ D, Nitin K. Agrawal 2 , Subarna K. Khatry ${ }^{3}$, Joanne Katz ${ }^{1}$, Steven C. LeClerq ${ }^{1,3}$, Bhola Rai ${ }^{3}$, Mark A. Reynolds ${ }^{4}$ and Luke C. Mullany ${ }^{1}$

\begin{abstract}
Background: In many low- and middle-income countries, insufficient human resources limit access to oral health services. Shifting clinical tasks to less specialized health professionals, such as community health workers, has been used as a strategy to expand the health workforce, especially in remote or underserved locations. The objective of this study was to evaluate the validity of periodontal examinations conducted by auxiliary nurse midwives in a rural home setting in Nepal.

Methods: Twenty-one pregnant women $<26$ weeks gestation from Sarlahi District, Nepal, underwent full mouth periodontal examinations measuring probing depth (PD) and bleeding on probing (BOP) on 6 sites per tooth by one of five auxiliary nurse midwives, who were trained for this study but had no previous training in dentistry. After a 15-min break, each participant was examined again by an experienced dentist. Measures of validity for PD and BOP were calculated comparing the pooled and individual auxiliary nurse midwives to the dentist. A multivariable GEE model estimated the effect of periodontal characteristics on agreement between the auxiliary nurse midwives and the dentist.
\end{abstract}

Results: Participant mean age was 22 years (SD: \pm 3 years), mean PD was $1.4 \mathrm{~mm}$ (SD: $03 \mathrm{~mm}$ ), and $86 \%$ of women had BOP (according to the dentist). Percent agreement, weighted kappa scores, and intraclass correlation coefficients for PD, with an allowance of $\pm 1 \mathrm{~mm}$, exceeded $99 \%, 0.7$, and 0.9 , respectively, indicating an acceptable level of agreement. Auxiliary nurse midwives tended to report higher PD scores relative to the dentist, although this over-estimation was small and unlikely to impact population-based estimates of important indicators of oral health status. GEE regression modeling indicated similar agreement for mandible vs. maxilla, left vs. right side, and PD $(\leq 2$ $\mathrm{mm},>2 \mathrm{~mm})$, and lower agreement for posterior teeth and lingual and proximal sites.

(Continued on next page)

\footnotetext{
* Correspondence: derchick@jhu.edu

${ }^{1}$ Department of International Health, Johns Hopkins Bloomberg School of Public Health, 615 N. Wolfe St, Baltimore, MD 21205, USA

Full list of author information is available at the end of the article
}

(c) The Author(s). 2020 Open Access This article is licensed under a Creative Commons Attribution 4.0 International License, which permits use, sharing, adaptation, distribution and reproduction in any medium or format, as long as you give appropriate credit to the original author(s) and the source, provide a link to the Creative Commons licence, and indicate if changes were made. The images or other third party material in this article are included in the article's Creative Commons licence, unless indicated otherwise in a credit line to the material. If material is not included in the article's Creative Commons licence and your intended use is not permitted by statutory regulation or exceeds the permitted use, you will need to obtain permission directly from the copyright holder. To view a copy of this licence, visit http://creativecommons.org/licenses/by/4.0/ The Creative Commons Public Domain Dedication waiver (http://creativecommons.org/publicdomain/zero/1.0/) applies to the data made available in this article, unless otherwise stated in a credit line to the data. 
(Continued from previous page)

Conclusion: Auxiliary nurse midwives were able to accurately conduct periodontal examinations in a rural home setting, suggesting the potential to shift tasks away from highly trained dentists and periodontal examiners in lowresource communities.

Trial registration: ClinicalTrials.gov Identifier: NCT01177111 (Nepal Oil Massage Study); registered on August 6th, 2010.

Keywords: Nepal, Oral health, Validity, Validation, Community-based

\section{Background}

Oral diseases constitute a major burden of chronic disease, collectively impacting half of the global population [1]. Leading causes of oral disease include dental caries, which affect a third of the population; gingivitis, a highly prevalent condition in children and adults; and severe periodontitis, a major cause of tooth loss, found in 10 to $15 \%$ of adults [2]. Disadvantaged communities, in both high- and low-income countries, have higher rates of oral disease and more limited access to oral health care, especially preventative services [3]. Critical knowledge gaps about the inequities in oral health care exist, including those related to the implementation of effective community-based intervention programs for oral diseases $[4,5]$.

In Nepal, like many low-income countries, oral health facilities, equipment, and qualified personnel, are in short supply [6]. Nepal has only two dentists per 100, 000 people, one of the lowest ratios among South Asian countries [7]. In such contexts, shifting clinical tasks to less specialized health care workers may help alleviate the human resource demand for research or programmatic purposes [8]. Community health workers (CHWs) have demonstrated the ability to safely and effectively conduct clinical diagnostic tasks, and deliver essential care, for a variety of diseases in low resource settings [9-11]. Yet fewer studies have evaluated the ability of CHWs to adopt oral health services, with most previous investigations focused on oral health promotion; diagnostic screening, typically for childhood caries; or, in limited cases, providing simple preventative services. Shifting other aspects of preventative or therapeutic clinical oral health care to CHWs, such as screening for periodontal diseases, have not been evaluated [12].

Periodontal assessment is an important component of routine oral health care for diagnosis and management of common conditions in adults like gingivitis and periodontitis. Periodontal disease has also been implicated as a risk factor for chronic diseases, including adverse pregnancy outcomes and cardiovascular disease [13-16]. Shifting responsibility for periodontal assessment to CHWs would require assessment of the validity of procedures prior to wider implementation, which is especially important considering the precise techniques involved in various clinical periodontal measurements.
Given the potential benefit of extending access to periodontal examination in community settings in lowresource areas, we estimated the validity of periodontal measurements collected by auxiliary nurse midwives relative to an experienced dentist in rural Sarlahi, Nepal.

\section{Methods}

We recruited twenty-one pregnant women $<26$ weeks gestation in a sub-area of Sarlahi District, Nepal, between January and November 2016. These women were enrolled in a community-based, prospective cohort study of maternal gingival inflammation and adverse pregnancy outcomes. Participants in this study were identified and determined eligible using the infrastructure of a large community-based randomized trial, the Nepal Oil Massage Study (NOMS) (NCT01177111), which was actively enrolling a population-based sample of pregnant women in Sarlahi District.

Five female auxiliary nurse midwives, all of whom had completed an 18-month government certified midwifery program and resided in the study area, were selected as data collectors for the study. The auxiliary nurse midwives had no previous training or professional experience in dentistry or clinical research. A training course for the auxiliary nurse midwives was designed and conducted by an experienced dentist (NA) from the Department of Dentistry, Institute of Medicine, Tribhuvan University, Kathmandu, Nepal. The training course covered basic dental anatomy, oral pathology, and the procedures for periodontal examination. Practical training included identification of plaque and calculus, signs of gingivitis, and measurement of probing depth (PD), bleeding on probing (BOP), and distance from the cemento-enamel junction to the free gingival margin (CEJ-GM). Auxiliary nurse midwives were also trained in clinical research methods and ethics for human subjects research. Training lasted 3-4 weeks and covered both classroom instruction and practice of periodontal techniques under the guidance of the dentist.

All study visits were conducted at participant's homes (Fig. 1) because of the wide dispersion of households and villages across this rural community and the impracticality of bringing participants to a central location. Auxiliary nurse midwives and an 

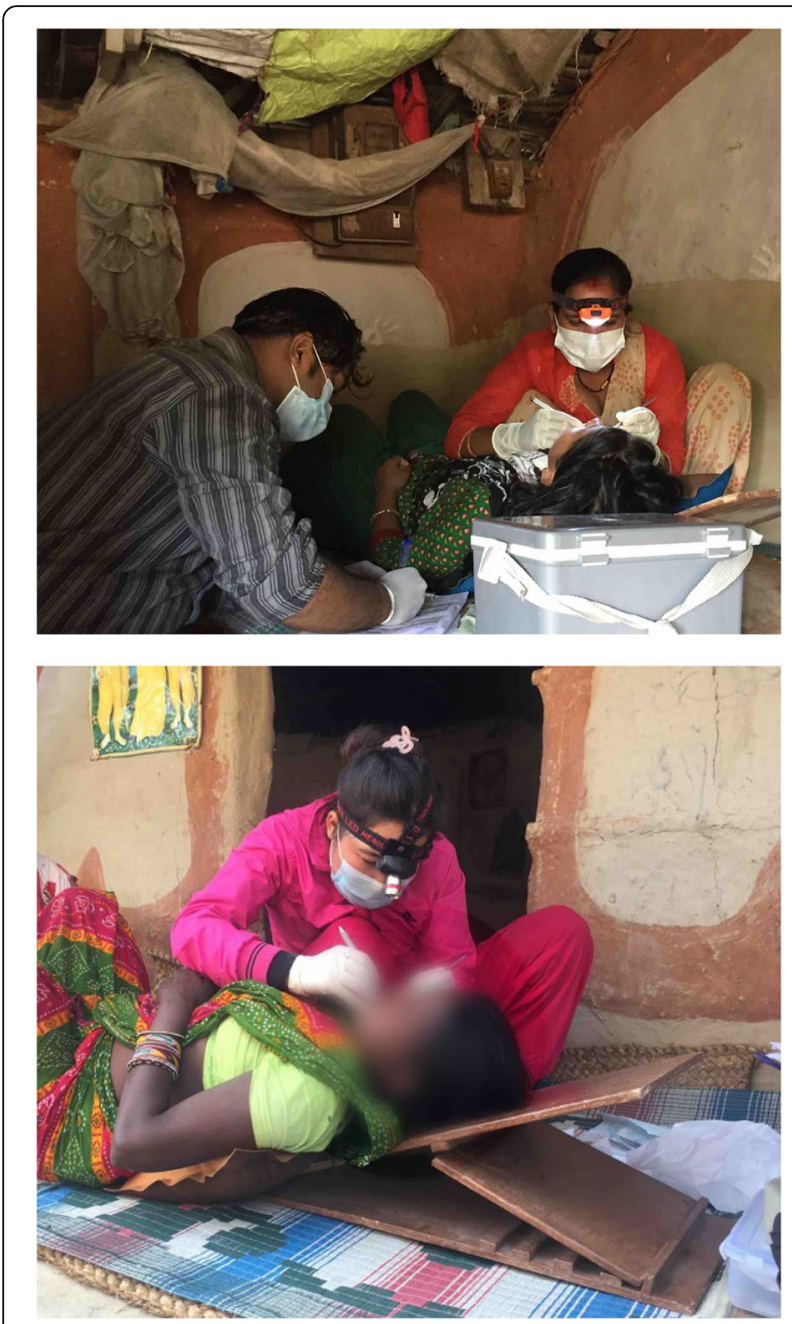

Fig. 1 Auxiliary nurse midwives conduct periodontal examinations on study participants at their homes in a rural area of Sarlahi District in the Terai region of Nepal

assistant traveled to participants' homes by motorbike, carrying with them all of the equipment required to conduct the exam. After the consent process, auxiliary nurse midwives asked the participant where in the home they felt most comfortable having the examination. A location was selected by the auxiliary nurse midwives to conduct the examination that maximized the available natural light and participant privacy. Often examinations were conducted inside the house on a bed or the floor in dim lighting. Ideal conditions were found in households with an enclosed courtyard, allowing for the exam to be conducted outdoors on the porch or ground, providing the most natural light. Electric lighting was present in very few households, and whether examinations were conducted inside or outside, auxiliary nurse midwives relied on batterypowered headlamps to illuminate the mouth.
Auxiliary nurse midwives conducted a full mouth examination on each of the participants in the household. After the examination, participants rinsed their mouth with water and rested for fifteen minutes. Finally, the dentist, who was masked to the results of the auxiliary nurse midwives, conducted a second examination in the household under the same conditions. Data were recorded on paper forms by a trained assistant and electronically entered by experienced data entry operators. Periodontal measurements were made using a color Williams probe (Hu-Friedy, Chicago, IL, USA). PD was measured on six sites per tooth (disto-, mid-, and mesial- aspects of buccal and lingual surfaces) and the CEJGM distance on two sites per tooth (mid- buccal and lingual aspects), excluding third molars. After probing each quadrant, the presence or absence of BOP was recorded for buccal and lingual surfaces of each tooth. PD values were recorded in millimeters from 1 to 10 , rounded to the next higher whole number. CEJ-GM distances were recorded similarly, with values of 0 to 10 $\mathrm{mm}$. If the free gingiva was coronal to the CEJ, the CEJGM measurement was recorded as 0. Clinical attachment loss (CAL) was calculated by summing PD and the CEJ-GM distance; the CEJ-GM distance was assigned a value of 0 for distal and mesial sites, where this measure was not collected.

After the examination, auxiliary nurse midwives had a conversation with participants to provide basic information on oral health, covering messages about oral selfcare, cessation from smoking, chewing tobacco, and use of betel nut, and care-seeking for preventative and therapeutic services. Messages on care seeking included sharing a list of the nearest government-run dental health care facilities. Participants with signs of periodontal disease, or other potential conditions identified by the auxiliary nurse midwives during the examination, were encouraged to improve their oral hygiene and seek care from one of these facilities.

Basic participant characteristics were reported as percentages. Differences between periodontal characteristics, as measured by the auxiliary nurse midwives and the dentist, were evaluated using paired t-tests or McNemar's chi-squared tests. Percent agreement was calculated between the pooled auxiliary nurse midwives and each individual worker compared to the dentist for perfect agreement and considering values of $\mathrm{PD} \pm 1 \mathrm{~mm}$ as agreement. Confidence intervals (95\%) for percent agreement were adjusted for clustering associated with the measurement of multiple teeth per participant using a generalized estimating equation (GEE) model. Kappa and weighted kappa (considering $\mathrm{PD} \pm 1 \mathrm{~mm}$ as agreement) statistics for PD were calculated, using tooth site as the unit of analysis, for pooled and individual auxiliary nurse midwives relative to the dentist. Confidence 
intervals (95\%) for weighted and unweighted kappa statistics were also adjusted for clustering by participant using a bootstrap approach (1000 replications). Similarly, intraclass correlation coefficients (ICC) and associated cluster-adjusted, bootstrapped 95\% confidence intervals were calculated for PD, using absolute agreement and tooth site as the unit of analysis, comparing the auxiliary nurse midwives to the dentist for perfect agreement and $\mathrm{PD} \pm 1 \mathrm{~mm}$ agreement. Sensitivity and specificity for the classification of tooth sites as PD $>2 \mathrm{~mm}$ were calculated for pooled and individual auxiliary nurse midwives vs. the dentist. A GEE model was used to estimate the effect of periodontal characteristics on agreement between the pooled auxiliary nurse midwives and dentist.

This study received ethical approval from the Institutional Review Board at Johns Hopkins Bloomberg School of Public Health (Baltimore, USA) and the Ethical Review Board of the Nepal Health Research Council (Kathmandu, Nepal). Our study adheres to the Standards for Reporting Diagnostic accuracy studies (STARD) 2015 guidelines.

\section{Results}

Twenty-one pregnant women $<26$ weeks gestation were enrolled in this study. The mean age of participants was 22 (SD: \pm 3 ) years (Table 1). A majority of women (62\%) were literate, $38 \%$ had no education, $38 \% 1-9$ years of schooling, and $24 \% 10$ or more years. Nearly threequarters $(71 \%)$ of participants lived in a house constructed from thatch, sticks, or bamboo, with the other

Table 1 Demographic characteristics

\begin{tabular}{lll}
\hline Characteristic & Frequency & Percent \\
\hline Age (years) & 7 & 33.3 \\
$<20$ & 11 & 52.4 \\
$20-24$ & 3 & 14.3 \\
$25-29$ & & \\
Literacy & 8 & 38.1 \\
$\quad$ No & 13 & 61.9 \\
$\quad$ Yes & & \\
Education (years) & 8 & 38.1 \\
$\quad 0$ & 8 & 38.1 \\
$\quad 1-9$ & 5 & 23.8 \\
$\quad \geq 10$ & & \\
House construction material & 15 & 71.4 \\
$\quad$ None, thatch, sticks, or bamboo & 68.6 \\
$\quad$ Wood planks, brick, or stones with mortar & 6 & \\
Latrine & & 47.6 \\
$\quad$ No latrine & 10 & 52.4 \\
$\quad$ Brick, concrete, or pit latrine & 11 & \\
\hline Demographic characteristics of study participants & &
\end{tabular}

Demographic characteristics of study participants
$29 \%$ in a house of wood, brick, or stone, and half (48\%) had no access to a latrine.

All participants had 28 teeth (excluding third molars), except for three women who were missing a single tooth (Table 2). Mean probing depth (PD) was $1.6 \mathrm{~mm}$ (SD: 0.3 ) with a range of 1 to $4 \mathrm{~mm}$ as measured by the auxiliary nurse midwives, and $1.4 \mathrm{~mm}$ (SD: 0.2 ) ranging 1 to $3 \mathrm{~mm}$ according to the dentist, a mean difference of 0.2 $\mathrm{mm}(p=0.02)$ (Fig. 2). When non-congruent, these absolute differences in PD were nearly universally $1 \mathrm{~mm}$, and roughly equally distributed in either direction. Collectively, the auxiliary nurse midwives identified one woman from the total twenty-one participants with at least one site with $\mathrm{PD} \geq 4 \mathrm{~mm}$, although the dentist measured these sites as $<4 \mathrm{~mm}$ and identified no other women as having any sites with $\mathrm{PD} \geq 4 \mathrm{~mm}$.

The mean number of sites with bleeding on probing (BOP) was 13.6 (SD: \pm 11.3$)$ and 11.4 (SD: \pm 12.0$)$ for the auxiliary nurse midwives and the dentist, respectively $(p=0.22)$. Most women, $86 \%$ according to the auxiliary nurse midwives, and $81 \%$ according to the dentist, had at least some bleeding $(p=0.56)$. The auxiliary nurse midwives identified two, and the dentist three, of 21 total participants as having $\geq 1 \mathrm{~mm}$ recession of the gingival margin from the CEJ. Therefore, mean clinical attachment loss (CAL) did not differ substantially from the measures of PD.

Overall percent agreement of PD for the auxiliary nurse midwives relative to the dentist was $63 \%$ (95\% CI: 58, 69\%) for perfect agreement and 99\% (95\% CI: 99, $100 \%$ ), for $\pm 1 \mathrm{~mm}$ agreement (Table 3). Percent agreement differed significantly $(p<0.001)$ when stratified by PD, ranging from $62 \%$ agreement for $\mathrm{PD}=1 \mathrm{~mm}$ to $48 \%$ for $\mathrm{PD}=$ $3 \mathrm{~mm}$. For the individual auxiliary nurse midwives vs. the dentist, percent agreement ranged from 58\% (95\% CI: 44, $72 \%$ ) to $69 \%$ (95\% CI: 54, 83\%) (Additional File 1) and percent agreement $\pm 1 \mathrm{~mm}$ ranged from $99 \%$ (95\% CI: 97 , $100 \%$ ) to $100 \%$ (Table 4). We calculated a design effect of 13.2 for the perfect agreement among the pooled auxiliary nurse midwives, indicating a high level of variation in PD between subjects. By individual participant, percent agreement and agreement $\pm 1 \mathrm{~mm}$ ranged from 40 to $90 \%$ and 96 to $100 \%$, respectively. Design effects for perfect percent agreement among the individual auxiliary nurse midwives ranged from 3.7 to 25.9 .

The kappa score for PD agreement between the pooled auxiliary nurse midwives and the dentist was 0.32 (95\% CI: $0.24,0.41)$ for perfect agreement, and 0.85 (95\% CI: $0.76,0.93$ ) for agreement within $\pm 1 \mathrm{~mm}$. Kappa scores for the five individual auxiliary nurse midwives compared to the dentist ranged from 0.24 (95\% CI: 0.06, $0.42)$ to $0.40(0.22,0.59)$ for perfect agreement, and 0.74 (95\% CI: $0.67,0.78$ ) to 1.0 for agreement within $\pm 1 \mathrm{~mm}$. The intraclass correlation coefficient (ICC) between the 
Table 2 Periodontal characteristics

\begin{tabular}{|c|c|c|c|}
\hline Characteristic & Auxiliary nurse midwives & Dentist & $P$-value \\
\hline \multicolumn{4}{|l|}{ Number of teeth ${ }^{a}$} \\
\hline Mean number of teeth & $27.9 \pm 0.36$ & $27.9 \pm 0.36$ & - \\
\hline \multicolumn{4}{|l|}{ Bleeding on probing (BOP) } \\
\hline Proportion of sites BOP & $13.6 \pm 11.3$ & $11.4 \pm 12.0$ & 0.22 \\
\hline$\geq 1$ site $\mathrm{BOP}($ No. $(\%))$ & $18(85.7)$ & $17(81.0)$ & 0.56 \\
\hline$\geq 1$ site $\&<10 \%$ of sites BOP (No (\%)) & $5(23.8)$ & $8(38.1)$ & - \\
\hline$\geq 10 \% \&<25 \%$ of sites BOP (No (\%)) & $8(38.1)$ & $5(23.8)$ & - \\
\hline$\geq 25 \%$ of sites BOP (No (\%)) & $5(23.8)$ & $4(19.1)$ & 0.56 \\
\hline \multicolumn{4}{|l|}{ Probing depth (PD) } \\
\hline Mean PD (mm) & $1.6 \pm 0.3$ & $1.4 \pm 0.2$ & 0.02 \\
\hline Proportion of sites with $\mathrm{PD} \geq 3 \mathrm{~mm}$ & $9.3 \pm 11.5$ & $4.2 \pm 6.0$ & 0.05 \\
\hline$\geq 1$ site $\mathrm{PD} \geq 4 \mathrm{~mm}$ (No (\%)) & $1(4.8)$ & $0(0.0)$ & - \\
\hline \multicolumn{4}{|l|}{ Clinical attachment loss $(\mathrm{CAL})^{\mathrm{b}}$} \\
\hline Mean CAL (mm) & $1.6 \pm 0.3$ & $1.4 \pm 0.2$ & 0.02 \\
\hline$\geq 1$ site $C A L \geq 4$ mm (No (\%)) & $2(9.5)$ & $1(4.8)$ & 0.56 \\
\hline
\end{tabular}

Data presented as mean \pm SD unless otherwise noted

${ }^{\text {a }}$ Excluding third molars

${ }^{\mathrm{b}}$ Direct site only

Periodontal characteristics of study participants as measured by the auxiliary nurse midwives and dentist

pooled auxiliary nurse midwives and the dentist was 0.43 (95\% CI: $0.35,0.51)$ for perfect agreement, and 0.94 (95\% CI: $0.91,0.98$ ) for agreement within $\pm 1 \mathrm{~mm}$. ICC values for the five individual auxiliary nurse midwives compared to the dentist ranged from 0.34 (95\% CI: 0.16 , $0.55)$ to 0.49 (95\% CI: $0.31,0.66)$ for perfect agreement, and 0.90 (95\% CI: $0.80,1.00)$ to 1.0 for agreement within $\pm 1 \mathrm{~mm}$.
Relative to the dentist, the pooled auxiliary nurse midwives classified individual tooth sites as $\mathrm{PD} \leq 2 \mathrm{~mm}$ or PD $>2 \mathrm{~mm}$ with $50 \%$ sensitivity and $96 \%$ specificity. For the five individual auxiliary nurse midwives, each relative to the dentist, sensitivity ranged from 19 to $85 \%$, and specificity from 92 to $99 \%$. However, auxiliary nurse midwives classified more sites as PD $>2 \mathrm{~mm}$ than the dentist, an average of $5.6 \%$ sites per participant vs. $2.5 \%$. Sensitivity and

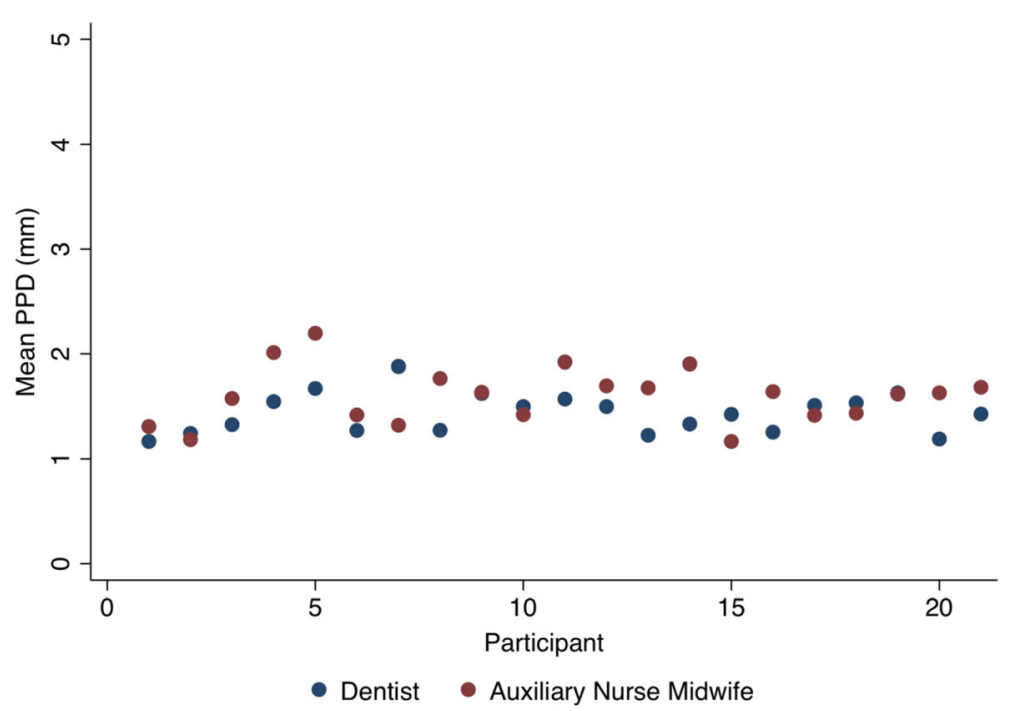

Fig. 2 Mean probing depth (PD) measured by individual auxiliary nurse midwives and dentist for each participant. Comparison of mean probing depth (PD) by participant as measured by individual auxiliary nurse midwives and dentist 
Table 3 Intraclass correlation coefficients and kappa statistics for pooled auxiliary nurse midwives vs. dentist

\begin{tabular}{lll}
\hline Measure & Point estimate & $95 \% \mathrm{Cl}$ \\
\hline Percent agreement & 63.3 & $57.5,69.1$ \\
Percent agreement $\pm 1 \mathrm{~mm}$ & 99.3 & $98.8,99.8$ \\
ICC & 0.43 & $0.35,0.51$ \\
ICC $\pm 1 \mathrm{~mm}$ & 0.94 & $0.91,0.98$ \\
Kappa & 0.32 & $0.24,0.41$ \\
Kappa $\pm 1 \mathrm{~mm}$ & 0.85 & $0.76,0.93$ \\
\hline
\end{tabular}

specificity of BOP were 53.8 and $91.5 \%$, respectively, for the pooled auxiliary nurse midwives relative to the dentist, with sensitivity ranging from 31 to $71 \%$, and specificity from 88 to $96 \%$, for individual auxiliary nurse midwives.

We modeled the relative risk (RR) of percent agreement for PD of the auxiliary nurse midwives relative to the dentist using a generalized estimating equation (GEE) regression model, including covariates for periodontal characteristics (Table 5). Covariates for jaw (maxilla, mandible), side (left, right), and probing depth $(\leq 2 \mathrm{~mm},>2 \mathrm{~mm})$ were not significantly related to percent agreement. PD measurements on posterior teeth and lingual surfaces were associated with an average reduction in percent agreement of 15\% (RR $0.85,95 \%$ CI: $0.81,0.90$ ) and 10\% (RR 0.90, 95\% CI: $0.86,0.95)$, respectively. Measurements on direct tooth site, relative to the proximal site, were associated with a $21 \%$ increase in agreement.

\section{Discussion}

Our results demonstrate that auxiliary nurse midwives with minimal training can satisfactorily conduct periodontal examinations at patient homes in rural Nepal. Percent agreement, weighted kappa scores, and intraclass correlation coefficients, with an allowance of $\pm 1 \mathrm{~mm}$, exceeded $99 \%$, 0.7 , and 0.9 , respectively, indicating an acceptable level of agreement. While the auxiliary nurse midwives tended to overestimate probing depth (PD) scores relative to the dentist, the magnitude of over-estimation was small $(0.2 \mathrm{~mm})$ and unlikely to impact population-based estimates of critical indicators. Relative to the dentist, the capacity of the auxiliary nurse midwives to distinguish sites with $\mathrm{PD}>2$ mm was less than ideal (sensitivity of 50\%); however, auxiliary nurse midwives demonstrated an excellent ability to discern sites with PD $\leq 2 \mathrm{~mm}$ (specificity 96\%). Sensitivity and specificity for bleeding on probing (BOP) data exhibited a similar pattern to PD, but should be interpreted with caution, due to the possible influence of the first examination on the subsequent one, given the short recovery interval (15 min) for each participant.

Globally, studies have shown that CHWs can safely and effectively deliver a range of health promotion services, diagnostic screenings, and therapeutic interventions in community-based, low-resource settings. These include, for example, ultrasound examination for diagnosis of obstetric risk factors, sign-based algorithms for assessment of omphalitis, and pneumonia case management $[9,10,17]$. However, the literature on training of $\mathrm{CHWs}$ to provide oral health care services is less well-developed relative to other areas, and is primarily limited to health promotion and use of simple diagnostic screening tools [12].

Available evidence from LMICs supports the ability of CHWs to conduct oral health promotion activities to teach proper oral hygiene behaviors, commonly brushing and flossing, and encourage care seeking. In the city of Rio Grande da Serra in southeastern Brazil, a pre-post intervention study showed that a training program and regular supervision for CHWs from a family health program led to improved oral health knowledge, oral hygiene behaviors, and care seeking and utilization of oral health services of women in the community [18]. Another pre-post intervention study, conducted in north Indian city of Chandigarh, reported that an oral hygiene education package delivered by local community-based

Table 4 Measures of probing depth agreement and sensitivity and specificity of probing depth (PD) $>2 \mathrm{~mm}$ and bleeding on probing (BOP) classification for individual auxiliary nurse midwives vs. dentist

\begin{tabular}{|c|c|c|c|c|c|c|c|c|c|c|c|}
\hline \multirow[b]{2}{*}{ ANM } & \multirow[b]{2}{*}{$N^{a}$} & \multirow[b]{2}{*}{$\begin{array}{l}\text { Tooth } \\
\text { sites }\end{array}$} & \multicolumn{3}{|l|}{ PD agreement } & \multicolumn{4}{|c|}{$\mathrm{PD}>2 \mathrm{~mm}^{\mathrm{b}}$} & \multicolumn{2}{|l|}{$\mathrm{BOP} \mathrm{P}^{\mathrm{b}}$} \\
\hline & & & Percent agreement \pm 1 mm & $\mathrm{ICC} \pm 1 \mathrm{~mm}$ & Kappa \pm 1 mm & No. sites & Sensitivity & Specificity & No. sites & Sensitivity & Specificity \\
\hline 1 & 4 & 669 & $100.0(99.5,100.0)$ & 1 & 1 & 9 & $55.60 \%$ & $95.30 \%$ & 126 & $71.40 \%$ & $89.00 \%$ \\
\hline 2 & 4 & 666 & $98.8(97.7,99.9)$ & $0.92(0.83,1.00)$ & $0.85(0.65,1.00)$ & 24 & $83.30 \%$ & $91.50 \%$ & 78 & $30.80 \%$ & $95.90 \%$ \\
\hline 3 & 4 & 666 & $98.8(97.4,100.0)$ & $0.90(0.80,1.00)$ & $0.74(0.67,0.78)$ & 27 & $38.10 \%$ & $94.70 \%$ & 54 & $66.70 \%$ & $87.80 \%$ \\
\hline 4 & 5 & 834 & $99.3(98.3,100.0)$ & $0.93(0.85,1.00)$ & $0.79(0.69,0.95)$ & 33 & $18.50 \%$ & $98.60 \%$ & 108 & $41.70 \%$ & $91.30 \%$ \\
\hline 5 & 4 & 672 & $99.7(99.4,100.0)$ & $0.97(0.95,1.00)$ & $0.92(0.79,1.00)$ & 13 & $84.60 \%$ & $97.00 \%$ & 30 & $60.00 \%$ & $93.50 \%$ \\
\hline
\end{tabular}

Data presented as point estimate $(95 \% \mathrm{Cl})$

${ }^{a}$ Number of participants assessed by both the auxiliary nurse midwives and dentist

${ }^{b}$ Number of sites with PD $>2 \mathrm{~mm}$ and BOP according to dentist's measurement

Validity measures comparing individual auxiliary nurse midwives to the dentist for probing depth \pm 1 mm agreement and sensitivity and specificity of probing depth (PD) $>2 \mathrm{~mm}$ and bleeding on probing (BOP) classification 
Table 5 Relationships between probing depth (PD) agreement and periodontal characteristics using a multivariable GEE model

\begin{tabular}{|c|c|c|}
\hline Variables & $\mathrm{RR}$ & $95 \% \mathrm{Cl}$ \\
\hline \multicolumn{3}{|l|}{ Jaw } \\
\hline Mandible & 0.96 & $0.92,1.00$ \\
\hline Maxilla & Ref & - \\
\hline \multicolumn{3}{|l|}{ Side } \\
\hline Right & 1.01 & $0.97,1.06$ \\
\hline Left & Ref & - \\
\hline \multicolumn{3}{|l|}{ Position } \\
\hline Posterior & 0.85 & $0.81,0.90$ \\
\hline Anterior & Ref & - \\
\hline \multicolumn{3}{|l|}{ Surface } \\
\hline Lingual & 0.90 & $0.86,0.95$ \\
\hline Facial & Ref & - \\
\hline \multicolumn{3}{|l|}{ Site } \\
\hline Direct & 1.21 & $1.15,1.28$ \\
\hline Proximal & Ref & - \\
\hline \multicolumn{3}{|c|}{ Probing depth } \\
\hline$>2 \mathrm{~mm}$ & 0.85 & $0.70,1.05$ \\
\hline$\leq 2 \mathrm{~mm}$ & Ref & - \\
\hline
\end{tabular}

Multivariable GEE model reporting relative risk (RR) of PD agreement between auxiliary nurse midwives relative to the dentist by periodontal characteristics

Anganwadi workers, who are responsible for maternal and child health education, led to a decrease in plaque and caries activity among children and an increase in self-reported oral hygiene behaviors [19].

A few studies have shown that CHWs in LMICs can utilize oral health diagnostic screening tools in communitybased settings, including to identify childhood caries or oral disease in the elderly. A study in Brazil found use of the Revised Oral Assessment Guide by community health workers, relative to a dentist, to have acceptable validity and reliability for the identification of oral health problems in elderly individuals in a clinic setting [20, 21]. In Thailand, CHWs, who had a secondary school level education, were successfully trained to provide oral health education, conduct root scaling and planing, sterilize instruments, control infection, and make referrals [22]. In Australia, several studies evaluated efforts to train Aboriginal Health Workers to expand oral health promotion, diagnostic screening, and delivery of basic interventions to remote and rural areas of the country [23]. A cluster randomized trial in Australia's Northern Territory reported that health promotion and application of fluoride varnish by Aboriginal Health Workers reduced dental caries in young children [24].

Findings from this study suggest that auxiliary nurse midwives, who far outnumber dentists and other oral health workers in Nepal, have the potential to expand access to oral health services in the community.
Auxiliary nurse midwives and other similar CHWs live nearby and work in health facilities at all levels of government across Nepal, including in rural areas where access to oral health care is generally lower. In 2018, there were 31,764 auxiliary nurse midwives registered with the Nepal Nursing Council, although staffing shortages for auxiliary nurse midwives exist across the health system [25]. For example, in 2015, the percent of sanctioned health posts for auxiliary nurse midwives that were filled ranged between 71 to $79 \%$ for different types of facilities from the zonal to the health post levels, with the exception of urban health centers, which were staffed at $36 \%$ capacity [26].

Beyond availability of auxiliary nurse midwives and similar CHWs, other issues would need to be considered by any effort to shift responsibility for delivery of oral health services to this cadre of CHWs. A few such questions include how effective oral health information provided by CHWs is at changing oral hygiene behaviors and reducing oral disease in this community; whether CHWs can safely and effectively provide basic oral health treatments in a community setting; how CHWs would refer patients requiring more skilled care to nearby dental health facilities; and whether delivery of oral health services by CHWs in rural communities provides cost savings to the health system.

Periodontal examination in a community-setting presents various challenges not found in a typical clinical setting, including difficult field conditions, such as the absence of a high-quality light source [27]. Some variability observed in the measures of validity in this study may be attributable to the field conditions. We identified lower agreement on posterior teeth, lingual surfaces, and proximal sites, areas that may be more difficult to measure accurately in low light. Alternatively, this variability could have resulted from the limited training of the auxiliary nurse midwives, or even normal inter-rater variability, as lower agreement for posterior, lingual, and proximal sites has also been seen in reliability studies utilizing highly trained periodontal examiners [28, 29].

A majority of women in our study had signs of gingival inflammation, but few had significant probing depths or attachment loss. This could be a result of the young age of the study population, which, at a mean of 22 , is low even for studies of the periodontal disease and adverse pregnancy outcome association [30]. Alternatively, the small sample size of this study may have played a role; data from the parent cohort study indicate a prevalence of $\geq 1$ site with PD $\geq 4 \mathrm{~mm}$ of over $8 \%$ [31]. As a result of the absence of moderate and severe disease, the bulk of our analyses focused on discriminating between low probing depth scores (i.e., $1-2 \mathrm{~mm}$ ), which are indicative of periodontal health. This limited our ability to fully explore the capacity of the auxiliary nurse midwives to 
accurately measure the full range of clinical periodontal parameters and distinguish between states of disease from health. Our assessment of the amount of measurement error associated with the study's auxiliary nurse midwives may be underestimated if higher probing depths are measured with lower reliability in this setting as has been documented elsewhere [27, 32].

In recent years, periodontal researchers have sought to improve data quality by designing a standardized process to assess periodontal examiners [33-36]. Validity and reliability studies have been used to determine if periodontal measurements conducted by periodontal examiners are consistent with a gold standard or within and between examiners [37, 38]. Yet a review of the periodontal literature, conducted by Hefti and Preshaw (2012), showed that only $30 \%$ of publications using the Gingival Index or Modified Gingival Index reported on examiner assessment, and almost none discussed the possible consequences of examiner validity or reliability on the outcome of the study [37]. Studies of the periodontal disease and adverse pregnancy outcomes association often do not report on examiner assessment, and those that do typically include a limited mention in methods section without estimates of uncertainty or information on study design used to collect these data. Our estimates of validity were generally comparable to those documented by similar studies of the periodontal disease and adverse pregnancy outcome association, although some achieved both weighted kappas and ICCs of over 0.9 [39].

A limitation of this study was its small sample size, which was restricted for logistical reasons. With additional participants we could have estimated reliability measures of intra-rater agreement for the repeated measurements of each auxiliary nurse midwife and inter-rater agreement between the study's five auxiliary nurse midwives. We prioritized validity over reliability because the auxiliary nurse midwives in this study had no previous experience in dentistry or clinical research. We could have also measured agreement using the subject as the unit of analysis, for example by classifying participants has having gingivitis or periodontitis, an approach that might have yielded more practical information for our parent study, which will take the subject as the primary unit of analysis in examining the relationship between periodontal disease and adverse pregnancy outcomes.

\section{Conclusion}

Our results suggest the potential to shift delivery of certain basic oral health services from dentists and other highly trained professionals to auxiliary nurse midwives or similar CHWs. Policy and programmatic decisions to task CHWs with provision of oral health care should be taken in the context of the multiple factors that affect the success of community health worker programs, including health systems factors (e.g., human resource structures, management and supervision policies), community factors (e.g., health beliefs, community mobilization), and national socioeconomic and political factors (e.g., political will, poverty) [11]. Increased efforts are needed to consider how CHWs could expand access to essential oral health knowledge and services in low-resource settings.

\section{Supplementary information}

Supplementary information accompanies this paper at https://doi.org/10. 1186/s12913-020-05276-5.

Additional file 1. Intraclass correlation coefficients and kappa statistics for individual auxiliary nurse midwives vs. dentist with perfect agreement Validity measures comparing individual auxiliary nurse midwives to the dentist for perfect probing depth agreement.

\section{Abbreviations}

BOP: Bleeding on probing; CEJ: Cemento-enamel junction; CAL: Clinical attachment loss; CHW: Community health worker; Cl: Confidence intervals; GEE: Generalized estimating eq.; GM: Gingival margin; LMICs: Low- and middle-income countries; ICC: Intraclass correlation coefficient; NOMS: Nepal Oil Massage Study; PD: Probing depth; RR: Relative risk; SD: Standard deviation

\section{Acknowledgements \\ The authors thank the auxiliary nurse midwives who conducted the periodontal examinations: Kaushila Chaudhary, Lalita Lama, Gayatri Mahat, Shanti Sharma, and Santoshi Kumari. Thank you to Roshan Chaudhary for serving as the laboratory technician. We also wish a special thank you to the women from Sarlahi District, Nepal, for participating in this study. This study was carried out in close collaboration with our implementing partner, Nepal Netra Jyoti Sangh, under the auspices of the Social Welfare Council of the Government of Nepal.}

\section{Authors' contributions}

DJE conceptualized and designed the study jointly with other authors, developed field implementation protocols, led data collection in the field, conducted the analysis, and wrote the manuscript. NKA conceptualized and designed the study jointly with other authors, trained and oversaw the auxiliary nurse midwives, and provided comments on the manuscript. SKK conceptualized and designed the study jointly with other authors, oversaw field implementation and ensured quality data collection, and provided comments on the manuscript. JK conceptualized and designed the study jointly with other authors, ensured quality data collection, advised on analytic approach, and provided comments on the manuscript. SCL conceptualized and designed the study jointly with other authors, supported overall implementation in the field, and provided comments on the manuscript. BR contributed to field implementation, ensured quality control of field procedures, and provided comments on the manuscript. MAR conceptualized and designed the study jointly with other authors, contributed to the analysis and interpretation of the results, and provided comments on the manuscript. LCM conceptualized and designed the study jointly with other authors, obtained funding for the study, oversaw implementation of data collection, obtained ethical approvals, advised on analytic approach, and provided edits and comments on the manuscript. All authors read and approved the final manuscript.

\section{Funding}

This work was supported by the National Institute for Child Health and Development [HD060712] and the Bill \& Melinda Gates Foundation [OPP1084399, OPP1131701]. Funders did not play a role in the study design, data collection, analysis, or interpretation, or writing of the manuscript. 


\section{Availability of data and materials}

All data files, codebooks, and related manuscripts are available from the JHU Data Archive (https://doi.org/10.7281/T1/ZPGBJW).

\section{Ethics approval and consent to participate}

Ethical approval was obtained from the Institutional Review Board (IRB) at the Johns Hopkins Bloomberg School of Public Health (\#6297) and from the independent Ethical Review Board of the Nepal Health Research Council (NHRC) (\#188/2015). All enrolled persons in this study were married. All provided written consent for participation, including married women under 18 years of age, who were considered emancipated minors according to local and international ethical review boards overseeing this project. NHRC approved the age of consent for participation in this study as at least 15 years.

\section{Consent for publication}

Not applicable.

\section{Competing interests}

The authors declare that they have no competing interests.

\section{Author details}

'Department of International Health, Johns Hopkins Bloomberg School of Public Health, 615 N. Wolfe St, Baltimore, MD 21205, USA. ${ }^{2}$ Department of Dentistry, Institute of Medicine, Tribhuhvan University, Maharajgunj, P.O. Box 152, Kathmandu, Nepal. ${ }^{3} \mathrm{Nepal}$ Nutrition Intervention Project-Sarlahi (NNIPS), Kathmandu, Nepal. ${ }^{4}$ Department of Advanced Oral Sciences and Therapeutics, University of Maryland School of Dentistry, $650 \mathrm{~W}$. Baltimore Street, 4th floor, Suite 4222, Baltimore, MD 21201, USA.

\section{Received: 20 December 2019 Accepted: 30 April 2020}

\section{Published online: 11 May 2020}

\section{References}

1. GBD 2015 Disease and Injury Incidence and Prevalence Collaborators. Global, regional, and national incidence, prevalence, and years lived with disability for 310 diseases and injuries, 1990-2015: a systematic analysis for the Global Burden of Disease Study 2015. Lancet. 2016; 388(10053):1545-602.

2. Petersen PE, Ogawa $H$. The global burden of periodontal disease: towards integration with chronic disease prevention and control. Periodontology 2000. 2012;60(1):15-39.

3. Petersen PE. Strengthening of oral health systems: oral health through primary health care. Med Princ Pract. 2014;23(Suppl 1):3-9.

4. Petersen PE, Kwan S. Equity, social determinants and public health programmes--the case of oral health. Community Dent Oral Epidemiol. 2011;39(6):481-7.

5. Jurgensen $\mathrm{N}$, Petersen $\mathrm{PE}$, Ogawa $\mathrm{H}$, Matsumoto S. Translating science into action: periodontal health through public health approaches. Periodontology 2000. 2012;60(1):173-87.

6. Kandelman D, Arpin S, Baez RJ, Baehni PC, Petersen PE. Oral health care systems in developing and developed countries. Periodontology 2000. 2012; 60(1):98-109.

7. Corbet EF, Leung WK. Epidemiology of periodontitis in the Asia and Oceania regions. Periodontology 2000. 2011;56(1):25-64.

8. World Health Organization. Task shifting: rational redistribution of tasks among health workforce teams: global recommendations and guidelines. Geneva: World Health Organization; 2008.

9. Mullany LC, Darmstadt GL, Katz J, et al. Development of clinical sign based algorithms for community based assessment of omphalitis. Arch Dis Child Fetal Neonatal Ed. 2006;91(2):F99-104.

10. Kozuki N, Mullany LC, Khatry SK, et al. Accuracy of home-based Ultrasonographic diagnosis of obstetric risk factors by primary-level health Care Workers in Rural Nepal. Obstet Gynecol. 2016;128(3):60412.

11. Haines A, Sanders D, Lehmann U, et al. Achieving child survival goals: potential contribution of community health workers. Lancet. 2007;369(9579): 2121-31.

12. Nash D, Ruotoistenmaki J, Argentieri A, et al. Profile of the oral healthcare team in countries with emerging economies. Eur J Dental Educ. 2008; 12(Suppl 1):111-9.
13. Offenbacher S, Katz V, Fertik G, et al. Periodontal infection as a possible risk factor for preterm low birth weight. J Periodontol. 1996;67(10 Suppl):1103-13.

14. Ide M, Papapanou PN. Epidemiology of association between maternal periodontal disease and adverse pregnancy outcomes--systematic review. J Periodontol. 2013;84(4 Suppl):S181-94.

15. Beck J, Garcia R, Heiss G, Vokonas PS, Offenbacher S. Periodontal disease and cardiovascular disease. J Periodontol. 1996;67(10 Suppl): 1123-37.

16. Lockhart PB, Bolger AF, Papapanou PN, et al. Periodontal disease and atherosclerotic vascular disease: does the evidence support an independent association?: a scientific statement from the American Heart Association. Circulation. 2012;125(20):2520-44.

17. Sazawal S, Black RE. Effect of pneumonia case management on mortality in neonates, infants, and preschool children: a meta-analysis of communitybased trials. Lancet Infect Dis. 2003;3(9):547-56.

18. Frazao P, Marques D. Effectiveness of a community health worker program on oral health promotion. Revista de saude publica. 2009;43(3): 463-71.

19. Raj S, Goel S, Sharma VL, Goel NK. Short-term impact of oral hygiene training package to Anganwadi workers on improving oral hygiene of preschool children in north Indian City. BMC Oral health. 2013;13:67.

20. Ribeiro MT, Ferreira RC, Vargas AM, e Ferreira EF. Validity and reproducibility of the revised oral assessment guide applied by community health workers. Gerodontology. 2014;31(2):101-10.

21. Andersson P, Hallberg IR, Lorefalt B, Unosson M, Renvert S. Oral health problems in elderly rehabilitation patients. Int J Dent Hyg. 2004;2(2):70-7.

22. Anumanrajadhon T, Rajchagool S, Nitisiri $\mathrm{P}$, et al. The community care model of the Intercountry Centre for Oral Health at Chiangmai, Thailand. Int Dent J. 1996;46(4):325-33.

23. Barnett $T$, Hoang $H$, Stuart J, Crocombe L, Bell E. Utilisation of oral health services provided by non-dental health practitioners in developed countries: a review of the literature. Community Dent Health. 2014;31(4):224-33.

24. Slade GD, Bailie RS, Roberts-Thomson K, et al. Effect of health promotion and fluoride varnish on dental caries among Australian aboriginal children: results from a community-randomized controlled trial. Community Dent Oral Epidemiol. 2011;39(1):29-43.

25. Ministry of Health and Population, Department of Health Services. Annual Report 2074/75 (2017/18). Kathmandu: Ministry of Health and Population; 2019.

26. Ministry of Health, Nepal, New ERA, Nepal, Nepal Health Sector Support Program, ICF. Nepal Health Facility Survey 2015. Kathmandu: Ministry of Health and Population; 2017.

27. Kingman $\mathrm{A}$, Loe $\mathrm{H}$, Anerud $\mathrm{A}$, Boysen $\mathrm{H}$. Errors in measuring parameters associated with periodontal health and disease. J Periodontol. 1991;62(8): 477-86

28. Andrade R, Espinoza M, Gomez EM, Espinoza JR, Cruz E. Intra- and interexaminer reproducibility of manual probing depth. Brazilian Oral Res. 2012; 26(1):57-63.

29. Lafzi A, Mohammadi AS, Eskandari A, Pourkhamneh S. Assessment of intraand inter-examiner reproducibility of probing depth measurements with a manual periodontal probe. J Dental Res Dental Clin Dental Prospects. 2007; 1(1):19-25.

30. Chambrone L, Guglielmetti MR, Pannuti CM, Chambrone LA. Evidence grade associating periodontitis to preterm birth and/or low birth weight: I. a systematic review of prospective cohort studies. J Clin Periodontol. 2011; 38(9):795-808.

31. Erchick DJ, Rai B, Agrawal NK, et al. Oral hygiene, prevalence of gingivitis, and associated risk factors among pregnant women in Sarlahi District, Nepal. BMC Oral Health. 2019;19(1):2.

32. Janssen PT, Faber JA, van Palenstein Helderman WH. Non-Gaussian distribution of differences between duplicate probing depth measurements. J Clin Periodontol. 1987;14(6):345-9.

33. Cohen DW, Ship II. Clinical methods in periodontal diseases based on a conference held on may 20-23, 1967 at University of Pennsylvania School of dental medicine. J Periodontol. 1967:38:576-795.

34. Page RC, Armitage GC, DeRouen TA, et al. Design and conduct of clinical trials of products designed for the prevention, diagnosis, and therapy of periodontitis. Chicago: American Academy of Periodontology; 1995. 
35. Polson AM. The research team, calibration, and quality assurance in clinical trials in periodontics. Ann Periodontol. 1997;2(1):75-82.

36. Kingman A, Albandar JM. Methodological aspects of epidemiological studies of periodontal diseases. Periodontology 2000. 2002;29:11-30.

37. Hefti AF, Preshaw PM. Examiner alignment and assessment in clinical periodontal research. Periodontology 2000. 2012;59(1):41-60.

38. Hill EG, Slate EH, Wiegand RE, Grossi SG, Salinas CF. Study design for calibration of clinical examiners measuring periodontal parameters. J Periodontol. 2006;77(7):1129-41.

39. Offenbacher S, Boggess KA, Murtha AP, et al. Progressive periodontal disease and risk of very preterm delivery. Obstet Gynecol. 2006;107(1):29-36.

\section{Publisher's Note}

Springer Nature remains neutral with regard to jurisdictional claims in published maps and institutional affiliations.

Ready to submit your research? Choose BMC and benefit from:

- fast, convenient online submission

- thorough peer review by experienced researchers in your field

- rapid publication on acceptance

- support for research data, including large and complex data types

- gold Open Access which fosters wider collaboration and increased citations

- maximum visibility for your research: over $100 \mathrm{M}$ website views per year

At BMC, research is always in progress.

Learn more biomedcentral.com/submissions 